\title{
Improved Deposition Efficiency of Cold-Sprayed CoNiCrAlY with Pure Ni Coatings and Its High-Temperature Oxidation Behavior after Pre-Treatment in Low Oxygen Partial Pressure
}

\author{
Kang-Il Lee* and Kazuhiro Ogawa \\ Fracture and Reliability Research Institute, Tohoku University, Sendai 980-8579, Japan
}

\begin{abstract}
In this study, the effect of nickel powder addition to cold sprayed CoNiCrAlY coatings was investigated. In order to reduce production cost of cold spray and improve the deposition efficiency of CoNiCrAlY coatings, pure nickel (Ni) powder was added to the CoNiCrAlY and the resulting powder was cold sprayed using nitrogen $\left(\mathrm{N}_{2}\right)$ as the working gas. Deposition efficiency was increased as compared with a CoNiCrAlY coating without Ni under the same spray conditions. The microstructural characterization and phase analysis of the feedstock powders and the as-sprayed coatings were carried out by scanning electron microscope (SEM) and energy-dispersive X-ray spectroscopy (EDX). In the SEM images, the particle boundaries between $\mathrm{Ni}$ and $\mathrm{CoNiCrAlY}$ in the as-sprayed coating were clearly observed. Also, a significant amount of the CoNiCrAlY powder was encapsulated in the coating. To confirm the oxidation behavior of CoNiCrAlY with the Ni coating, heat treatment was carried out at $1000^{\circ} \mathrm{C}$ in ambient air. After heating, most of the boundaries between $\mathrm{Ni}$ and CoNiCrAlY disappeared and many pores were generally observed in the coating by interdiffusion of the powders. Over time, most of these pores disappeared by interdiffusion; thus, the number of pores decreased and the hardness of the coatings increased. In the EDX analysis of the coatings, movement of elements was definitely confirmed. Furthermore, the elements of thermally grown oxide (TGO) were analyzed to confirm the effect of CoNiCrAlY with Ni coatings, and a large quantity of $\mathrm{NiO}$ was observed on the coating layer. Because $\mathrm{NiO}$ can lead to faster delamination of thermal barrier coatings (TBCs), pretreatment in low oxygen partial pressure was carried out to prevent the formation of excess $\mathrm{NiO}$. This pretreatment successfully prevented the growth of NiO TGO. [doi:10.2320/matertrans.T-M2014829]
\end{abstract}

(Received April 7, 2014; Accepted June 11, 2014; Published August 25, 2014)

Keywords: cold spray, CoNiCrAlY coating, nickel, thermally grown oxide, pretreatment, $N_{2}$ gas

\section{Introduction}

In gas turbine plants, an increase of the turbine inlet temperature is required in order to improve thermal efficiency and to reduce the emission of carbon dioxide. However, at high temperature, damage and failure of the nickel (Ni)-based superalloy gas turbine blades, such as melting, creep, and high temperature oxidation can be occurred. To prevent these problems, the surface temperature of these gas turbine blades must be protected by thermal barrier coatings (TBCs). To obtain low thermal conductivity, the TBCs are generally applied to a superalloy substrate and are composed of a metallic bond coat and a ceramic top coat. Normally, the fabrication of the TBCs involves the application of a MCrAlY ( $\mathrm{M}=\mathrm{Ni}, \mathrm{Fe}, \mathrm{Co}$, or their combination) bond coat to a Ni-based superalloy substrate, followed by a top coat of yttria-stabilized zirconia (YSZ). ${ }^{1-7)}$

In the TBCs, CoNiCrAlY as a bond coating is one of the most commonly used materials to improve the adhesive force and anti-hot corrosion between the bond coat and the top coat. CoNiCrAlY coatings are commonly applied using a low-pressure plasma spray (LPPS) or a high-velocity oxygen fuel (HVOF) spray technique. ${ }^{8)}$ However, owing to some disadvantages of these methods, such as the high cost and need for a vacuum chamber with the LPPS process or some degradation and the thick thermally grown oxide (TGO) of the HVOF spray process, the cold-spray process is a prospective candidate for coating preparation. ${ }^{4,8)}$

Cold spraying is a new technique that can be used for forming coatings as well as thick depositions. The cold-spray process was originally developed in the mid-1980s at the Institute of Theoretical and Applied Mechanics of the

*Corresponding author, E-mail: lee-kang-il@rift.mech.tohoku.ac.jp
Russian Academy of Sciences in Novosibirsk. ${ }^{9}$ ) Cold spraying is a process of applying coatings by exposing a metallic or dielectric substrate to a high velocity (more than $1000 \mathrm{~m} / \mathrm{s}$ ) jet of small (several micron to several ten micron) particles accelerated by a supersonic jet of compressed gas. In the cold-spray process, powder particles are accelerated by the supersonic gas jet at a temperature that is always lower than the melting point of the material, resulting in coating formation from particles in the solid state. Therefore, this process has advantages such as dense deposition, high deposition efficiency, and minimal oxidation. ${ }^{9-12)}$

Recently, it has been shown that CoNiCrAlY coatings produced by cold spraying using helium $(\mathrm{He})$ gas results in better deposition than the LPPS process. ${ }^{4)}$ However, it is difficult to keep costs down due to the use of expensive $\mathrm{He}$ gas. In the case of $\mathrm{N}_{2}$ gas, it is difficult to produce high hardness materials such as CoNiCrAlY due to the relatively lower kinetic energy of $\mathrm{N}_{2}$ gas. Therefore, in this study, pure $\mathrm{Ni}$ particles were added to the CoNiCrAlY and the resulting powder was cold sprayed using $\mathrm{N}_{2}$ in an effort to reduce the production costs and improve the deposition efficiency. ${ }^{8)}$ Furthermore, the high-temperature oxidation behavior of the CoNiCrAlY with Ni was evaluated.

After high-temperature oxidation tests of Ni-CoNiCrAlY coatings, a large quantity of $\mathrm{NiO}$ generated on $\mathrm{Ni}-\mathrm{CoNiCrAlY}$ coatings due to diffusion of superabundant Ni. Some literatures have suggested that pre-oxidation heat treatments in a low oxygen partial pressure environment could favor the preferential formation of a largely continuous transient alumina on the bond coat, reducing of preventing the formations of the other oxides such as spinels $\left(\mathrm{Ni}(\mathrm{Cr}, \mathrm{Al})_{2} \mathrm{O}_{4}\right)$, and nickel oxide $(\mathrm{NiO}){ }^{5)}$ In this study, it was applied to pre-heat treatment with a minimal oxygen environment to reduce formation of $\mathrm{NiO}$ utilized by a glass tube. 


\section{Experimental Procedure}

The polycrystalline Ni-based superalloy Inconel 738LC was used as the substrates. The substrates were subjected to a grit-blasting process using alumina media $100 \mu \mathrm{m}$ in diameter to clean and toughen the surface, thereby increasing its adherence. CoNiCrAlY and Ni-CoNiCrAlY as bond coat were deposited by cold spraying under identical conditions using spherical Co-32Ni-21Cr-8Al-0.5Y (AMDRY 9951, 5-37 $\mu \mathrm{m}$, Sulzer Metco, USA) powder particles and pure $\mathrm{Ni}(99.9 \%, 3-5 \mu \mathrm{m})$ powder, which was added to the CoNiCrAlY. The ratio of CoNiCrAlY to pure $\mathrm{Ni}$ was $9: 1 \operatorname{mass} \%$.

During cold spraying, the bond coat was manufactured using $\mathrm{N}_{2}$ gas with a gas temperature and pressure of $600^{\circ} \mathrm{C}$ and $4.0 \mathrm{MPa}$, respectively. Other spraying conditions included a powder feeding rate of $12.4 \mathrm{~g} / \mathrm{min}$, a traverse speed of $30 \mathrm{~mm} / \mathrm{s}$, and a stand-off distance of $20 \mathrm{~mm}$. Crosssections of the specimens were prepared for oxidation testing. These samples were then subjected to isothermal oxidation at $1000^{\circ} \mathrm{C}$ for 1,10 , and $100 \mathrm{~h}$. Furthermore, the same samples were subjected to isothermal oxidation in a glass tube (low oxygen partial pressure environments) at $1000^{\circ} \mathrm{C}$ for $100 \mathrm{~h}$ to prevent excessive formation of $\mathrm{NiO}^{5)}$ A cylindrical glass tube was produced with a volume of about $9.8 \mathrm{~cm}^{3}$, most of the internal atmosphere was removed by using the vacuum pump before the glass tube is completely cut off from outside. After pre-heat treatment in the glass tube, these samples were again subjected to isothermal oxidation in order to compare TGO formation with typical oxidation test at $1000^{\circ} \mathrm{C}$ for $100 \mathrm{~h}$. The experiments are summarized in Table 1.

After each oxidation test, the specimens were evaluated for TGO. Samples from the oxidation tests were mounted in a phenolic resin and manually mirror-polished for SEM observation and EDX analysis. The microstructures of the coating layers were examined by back-scattered electron (BSE) images with an FE-SEM (SU-70, Hitachi, Japan) equipped with EDX. The EDX analysis was carried out to evaluate the local elemental distributions in the coating layer.

The micro-hardness value of the coatings was measured using Vickers indentation (Shimadzu micro-hardness tester) at a loading of $0.98 \mathrm{~N}$ over $15 \mathrm{~s}$. The porosity of the coatings was determined by measuring the pores and the coating mass via an image analysis technique (Image J, National Institutes of Health, USA) on the SEM images.

\section{Results and Discussion}

\subsection{Microstructures of CoNiCrAlY and Ni-CoNiCrAlY coatings}

Figure 1 shows cross-sectional SEM images of typical CoNiCrAlY and Ni-CoNiCrAlY coatings by cold spray using $\mathrm{N}_{2}$ gas under the same conditions. In the CoNiCrAlY coating [Fig. 1(a)], insufficient bond coat of $20-50 \mu \mathrm{m}$ thickness was deposited by cold spraying, furthermore, large cracks and voids are observed at the interface between the coating and the substrate and in the coating layer itself due to the small plastic deformation of the particles with low particle velocity. Furthermore, the coating surface and thickness produced by
Table 1 Test program of isothermal oxidation tests.

\begin{tabular}{lccc}
\hline \multicolumn{1}{c}{ Type of test } & Environment & Temperature & Time \\
\hline $\begin{array}{l}\text { High temperature exposure } \\
\text { Pre-treatment }\end{array}$ & In air & $1000^{\circ} \mathrm{C}$ & $1,10,100 \mathrm{~h}$ \\
$\begin{array}{l}\text { High temperature exposure } \\
\text { (After pre-treatment) }\end{array}$ & In air & $1000^{\circ} \mathrm{C}$ & $100 \mathrm{~h}$ \\
\hline
\end{tabular}
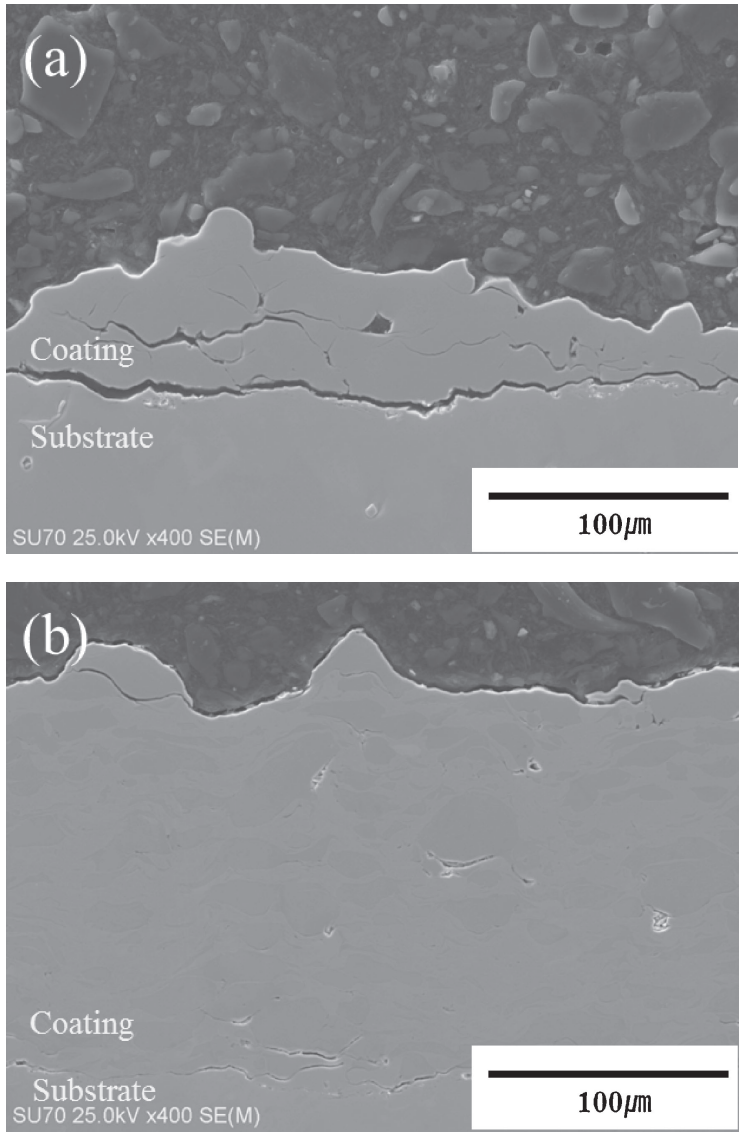

Fig. 1 Microstructures of the as-sprayed coatings under the same conditions: (a) CoNiCrAlY and (b) Ni-CoNiCrAlY.

cold spraying are extremely irregular; it was also confirmed that the deposition efficiency of the CoNiCrAlY coating was very low as compared with the Ni-CoNiCrAlY coating. On the other hand, in the case of the Ni-CoNiCrAlY coating [Fig. 1(b)], sufficient bond coat of $150-180 \mu \mathrm{m}$ thickness was deposited by cold spraying, furthermore, a very dense coating with well-distributed Ni particles was successfully deposited. Cracks and voids are nearly invisible at the interface between the coating and the substrate and in the coating layer itself. These results confirm that using $\mathrm{Ni}$ powder at a low particle velocity had a significant effect in terms of preventing the rebound energy of the CoNiCrAlY powder and increasing the deposition efficiency.

Figure 2 shows the BSE image of the as-sprayed NiCoNiCrAlY coating in these experiments. The coatings are composed of two major regions: the dark area is composed primarily of the CoNiCrAlY phase and the light area is composed of the nickel phase. The results of EDX analysis also indicate CoNiCrAlY in the dark area and nickel in the light area (Fig. 2). As can be seen from Fig. 2, it was difficult 


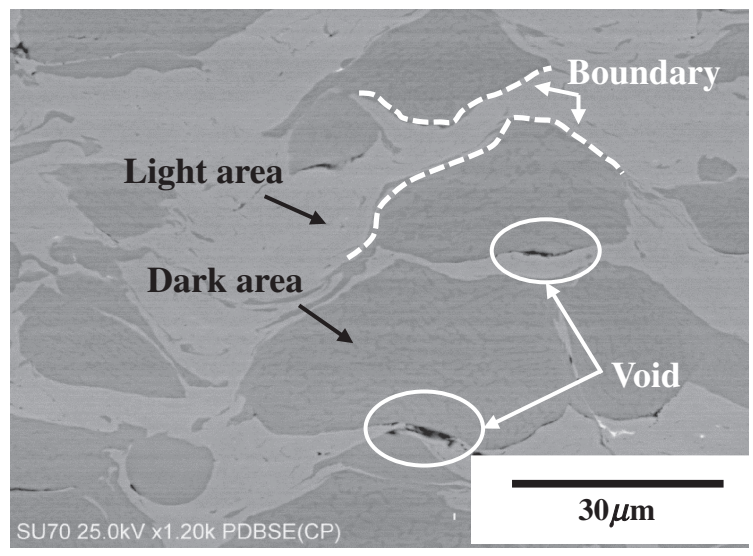

Fig. 2 Microstructure of the as-sprayed Ni-CoNiCrAlY coating.

to fabricate a homogeneous coating of Ni-CoNiCrAlY due to the large difference in hardness between the two phases. For these results, deposition efficiency of CoNiCrAlY is lower than that of nickel around $52-55 \%$ by image analysis technique. Also, a significant number of CoNiCrAlY particles were encapsulated in the coating. The boundary between the two types of particles was clearly observed, and voids were observed in junction of powders between $\mathrm{Ni}$ and $\mathrm{CoNiCrAlY}$.

\subsection{Oxidation behavior of Ni-CoNiCrAlY coatings}

Pre-oxidation of the bond coats without the YSZ layer was carried out through heat treatment at $1000^{\circ} \mathrm{C}$. The crosssectional microstructure of the oxidized Ni-CoNiCrAlY coatings presented remarkably different oxidation behavior as a function of heating time, as shown in Fig. 3. After the oxidation test, additional oxides were formed on the top surface of the coating layer. After heating for $1 \mathrm{~h}$, the boundaries between the $\mathrm{Ni}$ and $\mathrm{CoNiCrAlY}$ powder particles were unclear, whereas many tiny pores $(\leq 1 \mu \mathrm{m})$ were generally formed in the coating layer by interdiffusion, as shown in Fig. 3(a). The number of pores decreased with increasing heating time; however, an increase in the pore size was observed owing to the movement and combination of tiny pores. After heating for $100 \mathrm{~h}$, most of the pores in the coating layer disappeared; also, oxides were observed at the interface, as shown in Fig. 3(c).

The relationship between porosity ratio, hardness, and oxidation time is shown in Fig. 4. In the case of heat treatment from 1 to $50 \mathrm{~h}$, the porosity of the coating obviously increased as compared with the as-sprayed coating. However, after heat treatment for $100 \mathrm{~h}$, the porosity drastically decreased to less than $1 \%$ due to diffusion of atoms in the coating layer. From this result, the movement and mixture of atoms can be predicted in accordance with the heat treatment conditions of completely diffused together with Ni and CoNiCrAlY. Moreover, the movement of atoms gradually stabilized after heat treatment for $100 \mathrm{~h}$.

The hardness measurement results of the as-sprayed and oxidized coatings are also shown in Fig. 4. The hardness of the as-sprayed coatings was similar to that of the LPPS CoNiCrAlY coating. ${ }^{8}$ However, the value of error bar of the coatings was significantly large. This can be considered to be a result of the differences in hardness between the $\mathrm{Ni}$ and
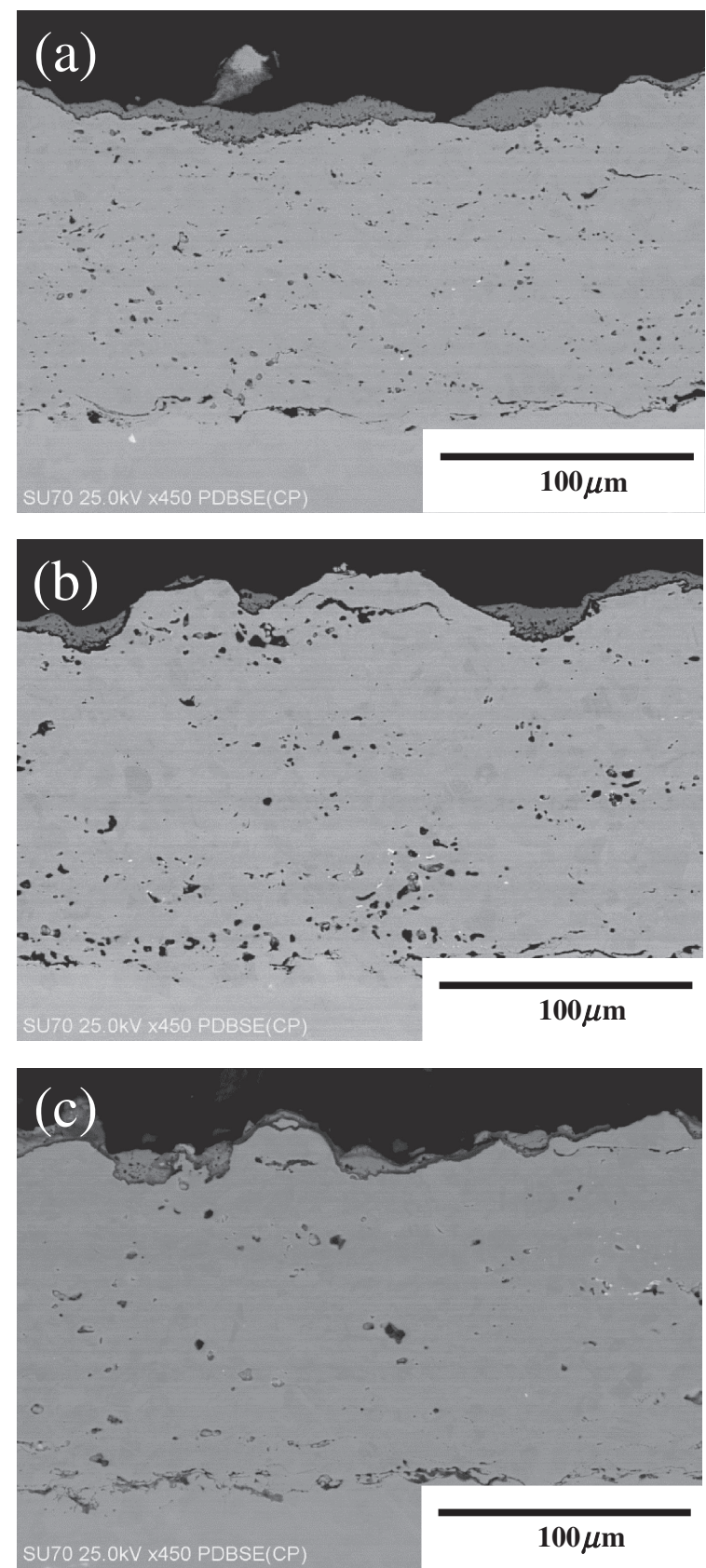

Fig. 3 Microstructures of Ni-CoNiCrAlY coatings after oxidation test at $1000^{\circ} \mathrm{C}$ for (a) 1, (b) 10 , and (c) $100 \mathrm{~h}$.

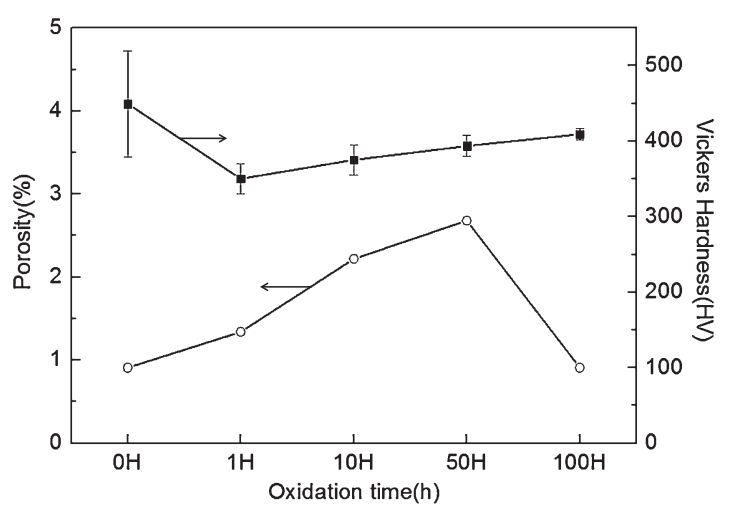

Fig. 4 Results of porosity and Vickers hardness. 

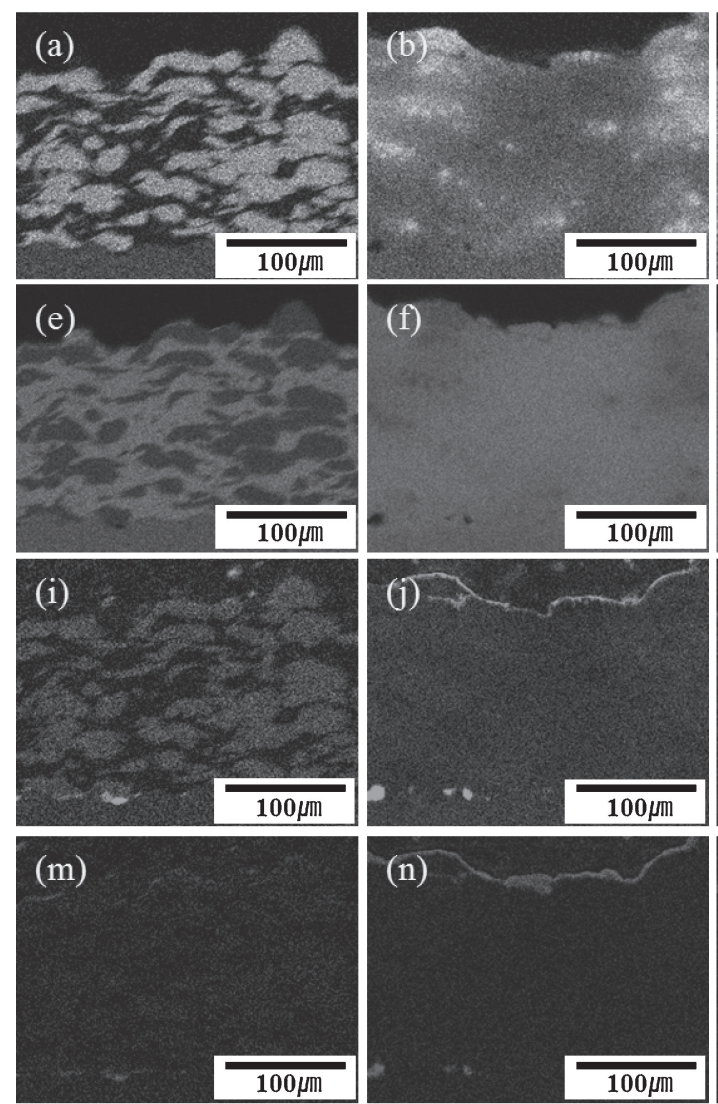

As-sprayed

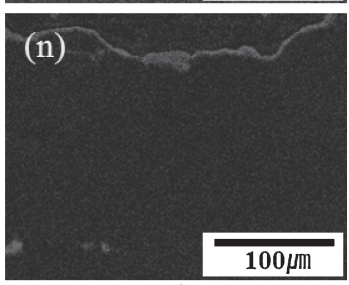

$1 \mathrm{~h}$
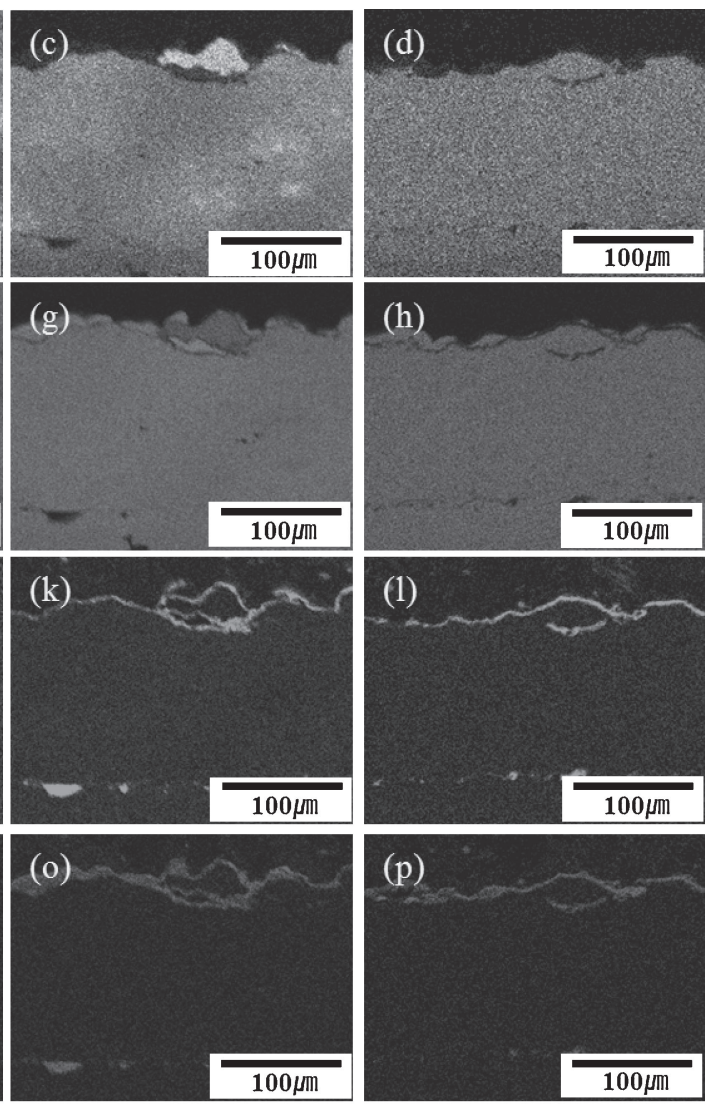

$10 \mathrm{~h}$

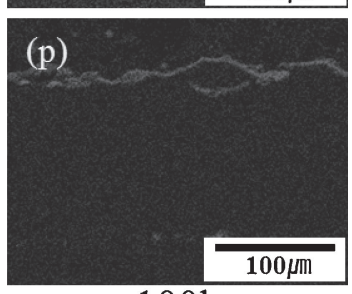

$100 \mathrm{~h}$

Fig. 5 EDX images of (a)-(d) cobalt, (e)-(h) nickel, (i)-(l) aluminum, and (m)-(p) oxygen as a function of heating time at $1000^{\circ} \mathrm{C}$.

CoNiCrAlY phases of the coatings. After heating for $1 \mathrm{~h}$, the hardness decreased by formation of pores with oxidation. After heating for 10 and $100 \mathrm{~h}$, the hardness was observed to increase with increasing heating time. Furthermore, the value of error bar of the hardness was stable as compared with the hardness at $1 \mathrm{~h}$ because of stabilization of the atoms. As a result, in the case of the Ni-CoNiCrAlY powder, the hardness increased with increasing heat treatment, which completely diffused together the $\mathrm{Ni}$ and CoNiCrAlY particles.

Figure 5 shows the element mapping results of the oxides grown on the surface and the movement of the elements as a function of heating time at $1000^{\circ} \mathrm{C}$. In the as-sprayed coating, the boundaries between $\mathrm{Ni}$ and $\mathrm{CoNiCrAlY}$ are clearly observed in Fig. 5(e). However, the two different materials are gradually mixed by interdiffusion of the powders with heat treatment of $100 \mathrm{~h}$. Consequently, after heat treatment for $100 \mathrm{~h}$, the movement of elements is stabilized and the elements are completely mixed; therefore, boundaries and agglomerated particles are not observed. As can be seen from the results, extensive interdiffusion occurred until uniform distribution was obtained at a certain temperature.

The different TGO compositions have different influences on the thermal cyclic behavior of TBCs. It has been reported that $\mathrm{Al}_{2} \mathrm{O}_{3}$ exhibits better adhesion to YSZ coatings and a lower growth rate than other oxides, such as $\mathrm{NiO}, \mathrm{Cr}_{2} \mathrm{O}_{3}$, and spinel. $\left.{ }^{4,13}\right) \mathrm{Ni} / \mathrm{Cr}$ mixed oxides in TGOs grow rapidly, resulting in high volumetric expansion stress in the YSZ coating, ${ }^{4,14)}$ which promotes the failure of TBCs. The continuous and uniform alumina-based TGO formed on the cold-sprayed bond coat protects the bond coat from fast oxidation.

TGO growth occurs at the surface when the metallic bond coat is exposed to high temperature in atmospheric air. Investigations ${ }^{15,16)}$ have shown that, as compared with other oxides, $\mathrm{Al}_{2} \mathrm{O}_{3}$ preferably forms at the bond coat surface because the oxidation of aluminum requires a lower oxygen partial pressure ${ }^{17)}$ and lower Gibbs free energy of formation $^{18)}$ than other metal components, such as $\mathrm{Ni}, \mathrm{Cr}$, etc. In this result, it was mainly formed $\mathrm{Al}_{2} \mathrm{O}_{3}$ on the surface; however, nickel oxides have also been observed in Figs. 5(h), $5(\mathrm{p})$.

The TGO cross-section and the corresponding element mapping and point analysis of the magnified TGO are shown in Fig. 6. Ni-CoNiCrAlY coatings produced TGO that is partially alumina with substantial amounts of $\mathrm{Ni}$, as shown in Fig. 6. The formation of the $\mathrm{Ni}$ oxides is concentrated on the alumina $\left(\mathrm{Al}_{2} \mathrm{O}_{3}\right)$ TGO. The result of the point analysis from Fig. 6 suggests the presence of a detrimental spinel-type mixed oxide. Owing to its low free energy of oxidation, $\mathrm{Al}_{2} \mathrm{O}_{3}$ will tend to form first on CoNiCrAlY bond coats. Therefore, the findings from Fig. 6 indicate that these mixed oxides formed at the very beginning of the oxidation process due to insufficient aluminum at the bond coat surface as a consequence of the Ni-CoNiCrAlY coating. The formation of an $\mathrm{Al}_{2} \mathrm{O}_{3}$-based TGO with a certain thickness can effectively hinder the diffusion of other metal components, such as $\mathrm{Cr}$, $\mathrm{Ni}$, etc., and subsequently hinder the formation of their oxides. The thickness of the $\mathrm{Al}_{2} \mathrm{O}_{3}$-based TGO thus plays a 



Fig. 6 Cross-sectional microstructure and the corresponding EDX mapping and point analysis of magnified TGO.

key role in controlling the diffusion of $\mathrm{Ni}, \mathrm{Cr}$ etc. and the formation of oxides. A stable $\mathrm{Al}_{2} \mathrm{O}_{3}$ layer to prevent the formation of other oxides produced by diffusion without $\mathrm{Al}$ depletion in the underlying superalloy is effective for suppressing the diffusion of $\mathrm{Ni}$ and $\mathrm{Cr}$ and subsequently the formation of the $\mathrm{Ni} / \mathrm{Cr}$ oxides. However, an unstable $\mathrm{Al}_{2} \mathrm{O}_{3}$ layer to prevent the formation of other oxides produced by diffusion on the Ni-CoNiCrAlY bond coat allows some diffusion of $\mathrm{Cr}, \mathrm{Ni}$, etc. to its surface after $\mathrm{Al}$ depletion occurs. As a result, $\mathrm{Ni} / \mathrm{Cr}$ oxides grow fast in spite of the formation of underlying $\mathrm{Al}_{2} \mathrm{O}_{3}$ scale. ${ }^{4}$

\subsection{Pretreatment in low oxygen partial pressure envi- ronment for thick $\mathrm{Al}_{2} \mathrm{O}_{3}$}

The previous experiment in atmospheric air furnace heat treatments at $1000^{\circ} \mathrm{C}$ formed mainly thick $\mathrm{Ni}$ oxides due to superabundant amounts and diffusion of Ni. These Ni oxides can lead to faster delamination between the top coat and bond coat in TBCs. Pretreatment in a glass tube was thus carried out to prevent formation of $\mathrm{Ni}$ oxides and encourage formation of a thick $\mathrm{Al}_{2} \mathrm{O}_{3}$ layer on the bond coat.

Figure 7 shows a specimen in the glass tube. This specimen with the glass tube was heat treated at $1000^{\circ} \mathrm{C}$ for $100 \mathrm{~h}$ in an atmospheric air furnace. Oxygen was removed as much as possible from the glass tube by a vacuum pump. The glass tube can prevent growth of other oxides by supplying minimum oxygen, thereby enabling thick $\mathrm{Al}_{2} \mathrm{O}_{3}$ oxide to form. After pretreatment in glass tube, almost similar phenomenon in pore and porosity was observed compared to typical oxidation test in the coating layer.

Figure 8(a) shows the TGO cross-section and the corresponding elemental mapping after heat treatment in the glass tube. The $\mathrm{Al}_{2} \mathrm{O}_{3}$ TGO layer was continuously formed with an

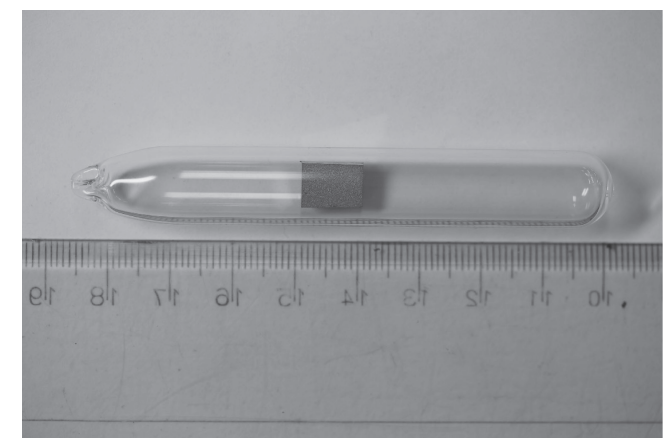

Fig. 7 As-sprayed specimen in glass tube for pretreatment.

average thickness of approximately $2 \mu \mathrm{m}$. The slight presence of other oxides such as $\mathrm{NiO}$ and $\mathrm{Cr}_{2} \mathrm{O}_{3}$ on the $\mathrm{Al}_{2} \mathrm{O}_{3}$ are confirmed after heat treatment in the glass tube. This result shows that the glass tube had a significant effect on the reduction of $\mathrm{Ni}$ oxides and the formation of a stable $\mathrm{Al}_{2} \mathrm{O}_{3}$ TGO.

After that, heat treatment of the specimen without the glass tube was carried out a second time at $1000^{\circ} \mathrm{C}$ for $100 \mathrm{~h}$ in an atmospheric air furnace to verify the effect of the pretreatment with the glass tube. As can be seen from Fig. 8(b), the TGO after heat treatment in the atmospheric air furnace was almost unchanged in comparison with the specimen after pretreatment. From these results, it is apparent that the stable $\mathrm{Al}_{2} \mathrm{O}_{3}$ oxide formed by the glass tube prevented the formation and continuous growth of other oxides, such as $\mathrm{NiO}, \mathrm{Cr}_{2} \mathrm{O}_{3}$, and spinel, after heat treatment in air.

The results of this study indicate that TBCs with a NiCoNiCrAlY bond coat after pretreatment should have a longer lifetime than those with a Ni-CoNiCrAlY bond coat before pretreatment. 

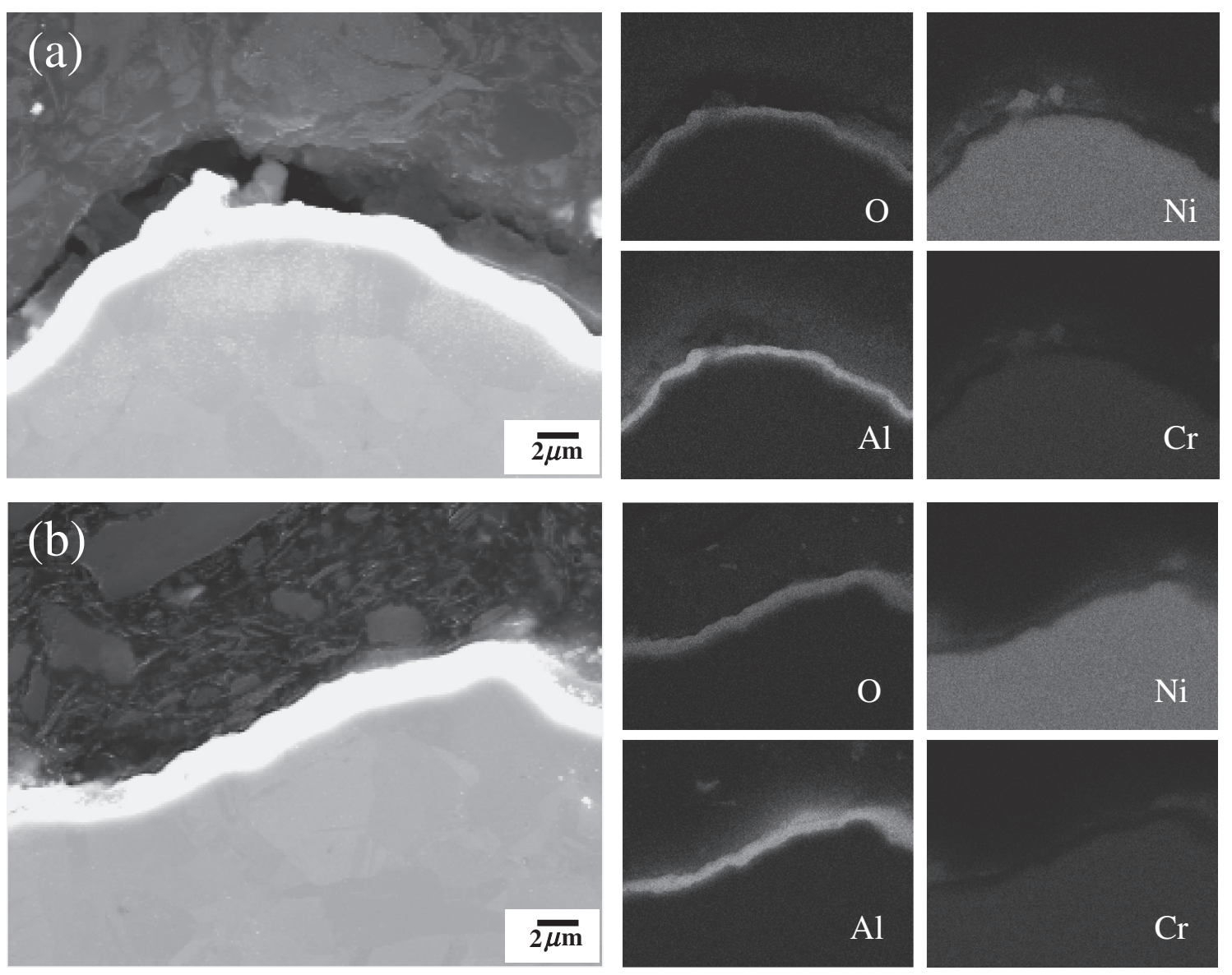

Fig. 8 Cross-sectional microstructure and the corresponding EDX mapping of magnified TGO (a) after pretreatment with glass tube (at $1000^{\circ} \mathrm{C}$ for $100 \mathrm{~h}$ ) and (b) after a second heat treatment after pretreatment.

\section{Conclusions}

In order to reduce production cost of cold spraying and improve the deposition efficiency, Ni-CoNiCrAlY coatings were successfully deposited on Ni-based superalloys by cold spraying using $\mathrm{N}_{2}$ gas. The results showed the possibility of obtaining a CoNiCrAlY coating at low energy by using $\mathrm{Ni}$. However, it was found that excessive $\mathrm{Ni}$ oxide formed on $\mathrm{Al}_{2} \mathrm{O}_{3}$ oxide after heat treatment. These $\mathrm{Ni}$ oxides can lead to faster delamination between the top coat and bond coat in TBCs. Therefore, pretreatment in low oxygen partial pressure environment was carried out to prevent formation of $\mathrm{Ni}$ oxides and encourage the formation of stable $\mathrm{Al}_{2} \mathrm{O}_{3}$. After that, heat treatment of the specimen without the glass tube was carried out a second time in an atmospheric air furnace to verify the effect of the pretreatment. After heat treatment in an atmospheric air furnace, the TGO was almost unchanged. Consequently, TBCs with a Ni-CoNiCrAlY bond coat after pretreatment should have a longer lifetime than those before pretreatment.

\section{REFERENCES}

1) A. Manap, A. Nakano and K. Ogawa: J. Therm. Spray Technol. 21 (2012) 586-596

2) D. Seo, K. Ogawa, Y. Nakao, H. Miura and T. Shoji: Surf. Coat. Technol. 203 (2009) 1979-1983.

3) M. Okazaki, S. Yamagishi, Y. Yamazaki, K. Ogawa, H. Waki and M.
Arai: Int. J. Fatigue 53 (2013) 33-39.

4) Y. Li, C. Li, G. Yang and L. Xing: Surf. Coat. Technol. 205 (2010) 2225-2233.

5) P. Puetz, X. Huang, R. S. Lima, Q. Yang and L. Zhao: Surf. Coat. Technol. 205 (2010) 647-657.

6) A. C. Karaoglanli, H. Dikici and Y. Kucuk: Eng. Fail. Anal. 32 (2013) 16-22.

7) J. Toscano, R. Vaben, A. Gil, M. Subanovic, D. Naumenko, L. Singheiser and W. J. Quadakkers: Surf. Coat. Technol. 201 (2006) 3906-3910.

8) M. Sone, H. Fukanuma, R. Huang and N. Ohno: Proc. Int. Therm. Spray Conf., ed. by R. S. Lima, A. Agarwal, M. M. Hyland, Y.-C. Lau, C.-J. Li, A. McDonald and F.-L. Toma, (2012) pp. 283-286.

9) A. Papyrin, V. Kosarev, S. Klinkov, A. Alkhimov and V. Fomin: Cold Spray Technology, (Elsevier, Russia, 2007) pp. 119-124.

10) H. Lee, H. Shin, S. Lee and K. Ko: Mater. Lett. 62 (2008) 1579-1581.

11) H. Kang and S. Kang: Scr. Mater. 49 (2003) 1169-1174.

12) S. V. Klinkov, V. F. Kosarev, A. A. Sova and I. Smurov: Surf. Coat. Technol. 202 (2008) 5858-5862.

13) R. D. Maier, C. M. Scheuermann and C. W. Andrews: Am. Ceram. Soc. Bull. 60 (1981) 555.

14) Y. Li, C.-J. Li, Q. Zhang, G.-J. Yang and C.-X. Li: J. Therm. Spray Technol. 19 (2010) 168.

15) A. Gil, V. Shemet, R. Vassen, M. Subanovic, J. Toscano, D. Naumenko, L. Singheiser and W. J. Quadakkers: Surf. Coat. Technol. 201 (2006) 3824 .

16) M. Matsumoto, T. Kato, K. Hayakawa, N. Yamaguchi, S. Kitaoka and H. Matsubara: Surf. Coat. Technol. 202 (2008) 2743

17) H. Yamano, K. Tani, Y. Harada and T. Teratani: J. Therm. Spray Technol. 17 (2008) 275.

18) F. Tang, L. Ajdelsztajn and J. M. Schoenung: Oxid. Met. 61 (2004) 219. 